\title{
Parental criticism, self-criticism and their relation to depressive mood: an exploratory study among a non-clinical population
}

\author{
Chiara Manfredi, ${ }^{1,2}$ Gabriele Caselli, ${ }^{1,2}$ Federica Pescini, ${ }^{1}$ Martina Rossi, ${ }^{1}$ Daniela Rebecchi, ${ }^{1}$ Giovanni Maria Ruggiero, ${ }^{1,2}$ \\ Sandra Sassaroli ${ }^{1}$
}

${ }^{1}$ Studi Cognitivi, Psychotherapy School, Milan; ${ }^{2}$ Sigmund Freud University, Milan, Italy

\begin{abstract}
Internalized self-criticism (ISC) has been identified as one dimension of depression and has been related to poor interpersonal functioning, severity of depressive symptoms among patients with a diagnosis of major depressive disorder, and suicidal behaviors. Finally, it has been indicated as a maintaining factor in depression, able to impair the efficacy of psychological treatment. The present study aimed to investigate the role of perceived parental criticism, perfectionistic concern over mistakes and ruminative brooding in predicting internalized self-criticism; in addition, we explored the predictive value of all the considered variables for depressive mood in a nonclinical population. The final model showed a complete mediation for concern over mistakes and ruminative brooding in the relationship between perceived parental criticism and ISC, with the final model explaining $32 \%$ of the variance. Moreover, ISC predicted the level of depressive symptoms over and above the contribution of the other variables considered. The findings suggest that a thinking style characterized by ruminative brooding and the tendency to be concerned with mistakes can facilitate the development of a self-critical person, more than a parental style perceived as critical. Moreover, the tendency to be self-critical may be more predictive of depressive symptoms than the other variables considered.
\end{abstract}

Key words: Self-criticism; Ruminative brooding; Depressive symptoms; Concern over mistakes; Parental criticism.

\section{Introduction}

Self-criticism has been linked to a number of psychological disorders, with depression being the most prominent, as well as other dysfunctional tendencies (Powers \& Zuroff, 1992). More specifically, internalized self-criticism (ISC) has been identified as a specific component of self-criticism and it has been defined as a form of self-

Correspondence: Chiara Manfredi, Studi Cognitivi, Psychotherapy School, Foro Buonaparte 57, 20121 Milan, Italy.

Tel: +39.02.4150998 - Fax +39.02.87238216.

E-mail: c.manfredi@studicognitivi.net

Citation: Manfredi, C., Caselli, G., Pescini, F., Rossi, M., Rebecchi, D., Ruggiero, G.M., Sassaroli, S. (2016). Parental criticism, selfcriticism and their relation to depressive mood: an exploratory study among a non-clinical population. Research in Psychotherapy: Psychopathology, Process and Outcome, 19(1):41-48. doi: 10.4081/ripppo.2016.178

Received for publication: 15 June 2015.

Accepted for publication: 24 December 2015.

This work is licensed under a Creative Commons Attribution NonCommercial 4.0 License (CC BY-NC 4.0).

CCopyright C. Manfredi et al., 2016

Licensee PAGEPress, Italy

Research in Psychotherapy:

Psychopathology, Process and Outcome 2016; 19:41-48

doi:10.4081/ripppo.2016.178 devaluation arising from a comparison between the present situation and internal personal standards (Thompson \& Zuroff, 2000). In the theory proposed by the authors, individuals with high levels of ISC focus on a negative view of a lacking self as a reaction to both success and failure: this is how ISC may maintain a global and negative self-judgment that can in turn facilitate the perseveration of depressive symptoms and maladaptive behavioral patterns.

Several studies have investigated the role of self-criticism in many psychological issues, such as anxiety disorders and eating disorders (Cox, Fleet, \& Stein, 2004; Cox, Mac Pherson, Enns, \& McWilliams, 2004; Dunkey \& Grilo, 2007; Dunkley, Masheb, \& Grilo, 2010; Fennig et al., 2008; Lobera, Estébanez, Fernandez, Bautista, \& Garrido, 2009; McCranie \& Hyer, 1995). Concerning mood disorders, cognitive pioneers have shown that negative judging and condemning automatic thoughts concerning the self are deeply related to depression (Beck, Rush, Shaw, \& Emery, 1979); furthermore, empirical research has confirmed the importance of self-criticism as a specific cognitive process and a marker feature of depressive disorders (Hartlage, Arduino, \& Alloy, 1998). Moreover, self-criticism has shown a strong correlation with the severity of depressive symptoms among patients with a diagnosis of major depressive disorder: it has been strongly related to suicidal behaviors and it has been indicated as a maintaining factor in depression, able to impair the efficacy of psychological treatment (Cox, Enns, \& Clara, 2004; Fazaa \& Page, 2003; Luyten et al., 2007; 
Marshall, Zuroff, McBride, \& Bagby, 2008; Parker \& Crawford, 2009).

There are some clinical constructs that can show partial overlapping with ISC, and thus can be characteristic of a self-critical person. More specifically, literature has shown discordant results investigating the relationship among ISC, perfectionistic concern over mistakes $(\mathrm{CM})$ and ruminative brooding (B), and trying to determine the role of each construct in predicting depressive symptoms. As the more maladaptive and dysfunctional aspect of perfectionism, CM has been defined as the tendency to react negatively to mistakes, to interpret mistakes as equivalent to failure, and to believe that one will lose the respect of others following failure (Frost, Marten, Lahart, \& Rosenblate, 1990). Research has shown that people high in perfectionistic CM react with more negative mood, lowered confidence and a greater sense that they should have done better when facing a mistake, compared to subjects low in perfectionistic CM. Furthermore, subjects scoring high on perfectionistic CM think that others seeing their performance will perceive them as less intelligent than people with low perfectionistic CM do (Frost et al., 1995). Even if perfectionistic CM is related to self-criticism, it is a conceptually distinct construct: while the first involves the striving to be perfect and to avoid mistakes or flaws, the latter does not inherently demand striving for perfection.

Ruminative brooding has been defined as a perseverative, negative and cyclic thinking style focused on personal problems, negative sensations and thoughts as well as their consequences (Nolen-Hoeksema \& Morrow, 1991). This kind of response typically involves narrowly focusing and ruminating on one's negative emotions, and in the case of negative emotions associated with personal failure or inadequacies there is an exaggerated focus on implications for self-worth, leading to overly severe judgments and criticisms of the self (Neff, 2003; Nolen-Hoeksema, 1991). In this view, B can be related to both ISC and depressive mood, even if it represents a different and distinct construct: while ISC implies a particular focus on what the self is missing in order to be better and to have better performance, $B$ represents a process and a way of thinking that can focus on others or on the circumstances, trying to understand the causes and the consequences of depressed mood. The relationship between ISC and B is still unclear: some studies have identified a mediating role of $\mathrm{B}$ in the relationship between ISC and depressive symptoms and others have found that ISC predicted depressive mood while B did not (e.g., Kasch, Klein, \& Lara, 2001; Olson \& Kwon, 2008; Spasojevic \& Alloy, 2001).

Moving from what research has shown to date, aiming at a deeper understanding of the role of ISC in predicting depressive symptoms, it is important to better investigate its links with other cognitive features such as $\mathrm{CM}$ and $\mathrm{B}$, and to define which ones among parental characteristics can represent vulnerability factors for the development of ISC.

Early experiences have been shown to influence per- sonal schemas about self, others and interpersonal relationships, and a parental style characterized by low care, high standards and frequent critiques has been associated with anxiety, depressive symptoms and negative self-schemas (Gibb, 2002; Rose \& Abramson, 1992). We can hypothesize that a peculiar worry about possible mistakes $(\mathrm{CM})$ and the tendency to ruminate upon possible failures (B) could be derived by learned relational scripts, that lead a person to relate to him/herself in the same way important people (i.e. parents) have done during childhood (Baldwin, 1992, 1997; Bowlby, 1980). In turn, being alerted about mistakes and going on to ruminate about the past can enhance the probability of being self-critical (ISC).

To our knowledge, no research to date has directly investigated the relationship between the level of criticism perceived during childhood and the development of ISC in adulthood. As far as we know, there are only two studies that have investigated these features, but they are focused on different conceptualizations of family environment, investigating parental verbal abuse and family attitude (Bolton, Barrowclough, \& Calam, 2009; Sachs-Ericsson, Verona, Joiner, \& Preacher, 2006); finally, one study investigated the relationship between parental criticism and depression, but it involved clinic-referred adolescents (Brewin, Andrews, \& Furnham, 1996).

Starting from these findings, the present study aimed at understanding how perceived parental criticism can affect the development of ISC as well as better investigating the consequences of levels of ISC on depressive symptoms, controlling for $\mathrm{CM}$ and ruminative $\mathrm{B}$. All the variables included in the study have shown interrelations, thus a deeper and more specific understanding of the relationship between parental criticism, CM, B, ISC and depressive symptoms may be useful to better focus clinical interventions. Knowing which component contributes to depressive symptoms, and to which extent, can facilitate the tailoring of a specific and focused interventions on antecedents that can facilitate or maintain depressive symptoms.

More specifically, we hypothesized that: i) the tendency to be concerned about possible mistakes (CM) and ruminate on past failures (B) may mediate the relationship between perceived parental criticism and ISC; ii) the effects of $\mathrm{B}$ and $\mathrm{CM}$ in predicting the level of depressive mood may be mediated by the levels of ISC, confirming previous studies that showed an interrelation between these variables (e.g., Kasch et al., 2001; Olson \& Kwon, 2008; Spasojevic \& Alloy, 2001).

\section{Methods}

\section{Participants}

The sample consisted of 194 non-clinical subjects (55 males and 139 females) aged between 17 and 67 years $[\mathrm{mean}=35.9$, standard deviation $(\mathrm{SD})=9.55]$. Data were 
collected through the web, uploading the questionnaires on a survey platform and spreading the URL among social networks and websites. Thirty-four subjects left some questionnaires incomplete and were thus excluded from data analyses. The average numbers of years of education of the sample was $16.13(\mathrm{SD}=3.37$; range $=8-20)$ and was entirely Caucasian.

\section{Self-report instruments}

All the self-report measures administered for the purpose of this research were collected together in a batch that included the following.

Levels of self-criticism scale (LOSCS; Thompson \& Zuroff, 2004). This is a scale with two subscales: ISC and comparative self-criticism (CSC): while the first is conceptualized as a negative view of the self in comparison with internal, personal standards, the latter is defined as a negative view of the self in comparison with others. The levels of self-criticism scale contains 22 items (12 for CSC and 10 for ISC). Each item consists of a statement, and participants indicate how much the statement describes them on a Likert scale ranging from 1 (not at all) to 7 (very well). Thompson and Zuroff (2000) reported good reliability with Cronbach's alpha coefficients of 0.81 for CSC and of 0.87 for ISC. They also reported a moderate correlation between CSC and ISC $(r=0.45)$. For the present study we used an Italian version translated and approved by the authors; moreover, only ISC was administered to the subjects and it showed a good reliability, with a coefficient alpha of 0.84. Examples of items of the ISC subscale are When I don't succeed, I find myself wondering how worthwhile I am and I get very upset when I fail.

Beck depression inventory (BDI; Beck, Ward, Mendelson, Mock, \& Erbaugh, 1961). This is a 21-item self-report instrument assessing the common affective, cognitive, behavioral and somatic symptoms of depression. Respondents are required to indicate the degree to which they have been bothered by each symptom during the past week including today. Each symptom is rated on a 4-point scale ranging from 0 (not at all) to 3 (severely). Total scores range from 0 to 63 , with higher scores corresponding to higher levels of depressive symptoms. Beck depression inventory has been used extensively in both clinical and non-clinical populations and has shown good psychometric properties (Beck, Steer, \& Garbin, 1988). For the present study the Italian version of the questionnaire was used (Ghisi, Flebus, Montano, Sanavio, \& Sica, 2006). Beck depression inventory in out sample showed good internal consistency (Cronbach's $\alpha=0.87$ ).

Perceived criticism inventory (PCI; Apparigliato, Ruggiero, \& Sassaroli, 2007). This is a self-report instrument comprising 4 subscales, investigating: i) the amount of criticism experienced, ii) the critical themes, iii) how criticism has been expressed, and iv) the degree of personal agreement or disagreement with others' disapproval. For the purpose of this study, we administered only the subscale investigating the amount of parental criticism experienced by the subjects (PCI-Q), with 11 items describing a parental attitude characterized by blame and criticism towards children's choices and behaviors. Subjects are required to evaluate the frequency of these critiques as performed by their parents on a 5-point scale, ranging from 1 (never) to 5 (always). The measure has demonstrated good psychometric properties (Apparigliato et al., 2007); in our sample it showed a good reliability, with a coefficient alpha of 0.94 .

Ruminative responses scale (RRS) of the response style questionnaire (RSQ; Nolen-Hoeksema \& Morrow, 1991). This is a 22-item sub-scale of the 71-item RSQ, which measures the propensity to ruminate in response to depression. Respondents are required to indicate the degree to which they engage in a ruminative thinking style when feeling depressed. Each item is rated on a 4-point scale ranging from 1 (almost never) to 4 (always). Total scores range from 22 to 88 , with higher scores corresponding to higher levels of rumination. The sub-scale possesses good psychometric properties and has been extensively used (Just \& Alloy, 1997; Nolan, Roberts, \& Gotlib, 1998; Nolen-Hoeksema \& Davis, 1999). Recent research has suggested further dividing RRS into two subscales, ruminative brooding and reflections, both showing good reliability ( $\alpha=0.82$ and 0.85 , respectively). In this study we used the Italian version by Palmieri, Gasparre, and Lanciano (2007); both the subscales in our sample showed good reliability ( $\alpha=0.80$ and 0.73 , respectively).

Multidimensional perfectionism scale (MPS; Frost et al., 1990). This scale provides six subscales for a multidimensional assessment of perfectionism: $\mathrm{CM}$, personal standards (PS), parental expectations (PE), parental criticism (PC), doubts about actions (D), and organization (O). Since CM has been indicated as the central cognitive feature of perfectionism, for the purposes of this research we administered only this subscale, with 9 items answered on a 5-point agreement scale ranging from 1 (completely agree) to 5 (completely disagree). Internal consistency has ranged from good to excellent for each of the subscales $(\alpha s=0.77-0.93)$ and the total perfectionism score $(\alpha=0.90$; Frost et al., 1990); internal consistency in our sample was $\operatorname{good}(\alpha=0.90)$.

\section{Procedure}

The research project was approved by the ethics committee of the Italian Research Center Studi Cognitivi. Participants received the research project content via on-line distribution and Internet advertising and all took part on a voluntary and unpaid basis. Questionnaires were distributed both via e-mails and using an on-line survey platform that allowed participants to complete all the questionnaires at home and assured them of complete anonymity. The research project was explained to participants in a written introduction as an investigation on the relationships between parental criticism, self-criticism and de- 
pressive mood. All participants were informed that data provided in the research project would be anonymous and that they could withdraw at any time if they wished. Following a brief introduction regarding the aim of the research project, participants provided informed consent and were instructed to complete the questionnaires anonymously. All participants had the possibility to contact the authors via e-mail for debriefing and to receive more details about the research project.

\section{Statistic analyses}

Missing and incomplete data were excluded from the analyses. The first part of the analyses involved data description and the computing of correlational analyses. In order to investigate the relationship between parental criticism, B, CM, ISC and depressive symptoms, and to test the possible mediating role of ruminative $\mathrm{B}$ and $\mathrm{CM}$ in the relationship between parental criticism and depressive symptoms, we run two meditational analyses using INDIRECT script version 4.1 for SPSS version 16.0 for Windows (Preacher \& Hayes, 2008).

\section{Results}

\section{Data description}

An inspection of histograms, skewness and kurtosis showed that all the variables assessed were normally distributed. Descriptive statistics and correlational analyses for all the variables are presented in Table 1. Pearson product-moment correlations showed that both ISC and BDI were positively correlated with perceived parental criticism, B and CM. There were no significant mean differences for all the variables considered if comparing males with females and considering different age ranges.

\section{Mediational analysis 1: effect of perceived parental criticism, concern over mistakes and ruminative brooding on internalized self-criticism}

To investigate whether the effect of perceived parental criticism could be accounted by $\mathrm{CM}$ and $\mathrm{R}$ we used a meditational analysis (Figure 1). This allows verification of the extent to which a proposed mediator carries the influence of an independent variable to a dependent variable. In our model, parental criticism was entered as the independent variable, ISC was entered as the dependent variable and CM and B were entered as mediators. Statistical analyses were carried out using INDIRECT script version 2.13 for SPSS version 21.0 for Windows (Hayes, 2013).

The bootstrap test of indirect effects confirmed that $\mathrm{CM}$ and $\mathrm{B}$ mediated the effect of parental criticism on ISC (Figure 1). The Sobel test was statistically significant (B: $z=2.67, \mathrm{P}=0.01 ; \mathrm{CM}: z=4.29, \mathrm{P}=0.00$; Total: $z=5.32$, $\mathrm{P}=0.00$ ) with indirect effect estimate (IE) for $\mathrm{B}=0.10,95 \%$ confidence interval (CI) $(0.02,0.17)$, for $\mathrm{CM}=0.19,95 \%$ CI $(0.12,0.30)$ and for total $=0.29,95 \%$ CI $(0.19,0.41)$. The mediation of $\mathrm{B}$ and $\mathrm{CM}$ was significant and the path from perceived parental criticism to ISC was not significant when controlling for B and CM, suggesting a complete mediation relationship.

\section{Mediational analysis 2: effect of perceived parental criticism, concern over mistakes, ruminative brooding and internalized self-criticism on depressive symptoms}

To investigate whether levels of depressive symptoms could be accounted for by levels of ISC, we used the same mediational approach as in the previous analysis. In our model, B and CM were entered as independent variables in turn, with one entered as the independent variable and the other entered as covariate, perceived parental criticism was entered as a covariate, depressive symptoms were entered as the dependent variable and ISC was entered as the mediator (Figures 2 and 3, respectively). The bootstrap test of indirect effects confirmed that ISC mediated the effect of B and $\mathrm{CM}$ on depressive symptoms (Figures 2 and 3). IE estimate was $0.15,95 \% \mathrm{CI}(0.07,0.26)$ considering $\mathrm{CM}$ as the independent variable and $0.16,95 \% \mathrm{CI}(0.05,0.35)$ considering $\mathrm{B}$ as the independent variable. The mediation of ISC was significant and the path from $\mathrm{CM}$ and $\mathrm{B}$ to depressive symptoms was not significant when

Table 1. Means, standard deviations, and two-tailed Pearson product-moment correlations of study variables ( $\mathrm{n}=194)$.

\begin{tabular}{lcccccc}
\hline & Mean score & SD & BDI & PCI-Q & RRS-B & MPS-CM \\
\hline ISC & 37.83 & 11.27 & $0.508^{* *}$ & $0.275^{* *}$ & $0.421^{* *}$ & $0.543^{* *}$ \\
\hline BDI & 7.14 & 6.03 & - & $0.246^{* *}$ & $0.349^{* *}$ & $0.362^{* *}$ \\
\hline PCI-Q & 27.28 & 9.83 & - & - & $0.410^{* *}$ & $0.387^{* *}$ \\
\hline RRS-B & 10.32 & 3.21 & - & - & - & $0.473^{* *}$ \\
\hline MPS-CM & 20.89 & 7.10 & - & - & - \\
\hline
\end{tabular}

SD, standard deviation; BDI, Beck depression inventory; PCI-Q, parental criticism experienced by the subjects; RRS-B, ruminative responses scale-brooding; MPS-CM, multidimensional perfectionism scale-concern over mistakes; ISC, internalized self-criticism. ${ }^{* *}$ Correlation is significant at a 0.01 level. 


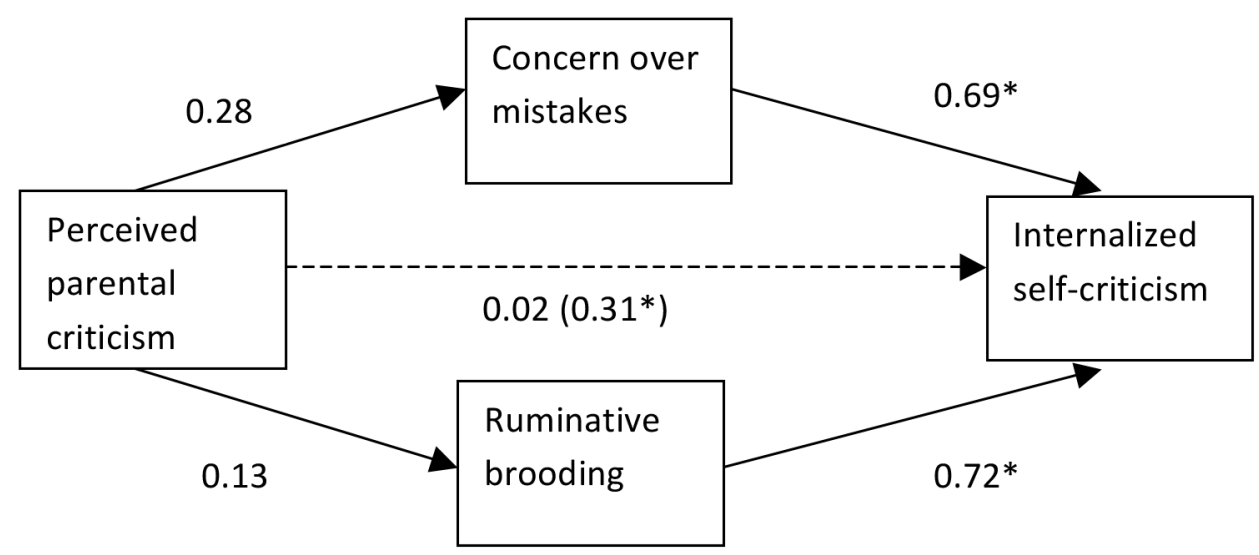

Figure 1. Changes in concern over mistakes and ruminative brooding completely mediated the effect of perceived parental criticism on change in internalized self-criticism. Parameter estimates are standardized coefficients. The value in parentheses is the standardized coefficient of the direct effect of perceived parental criticism without concern over mistakes and ruminative brooding entered in the model. Bootstrap samples $=1000$. $* \mathrm{P}<0.05$.

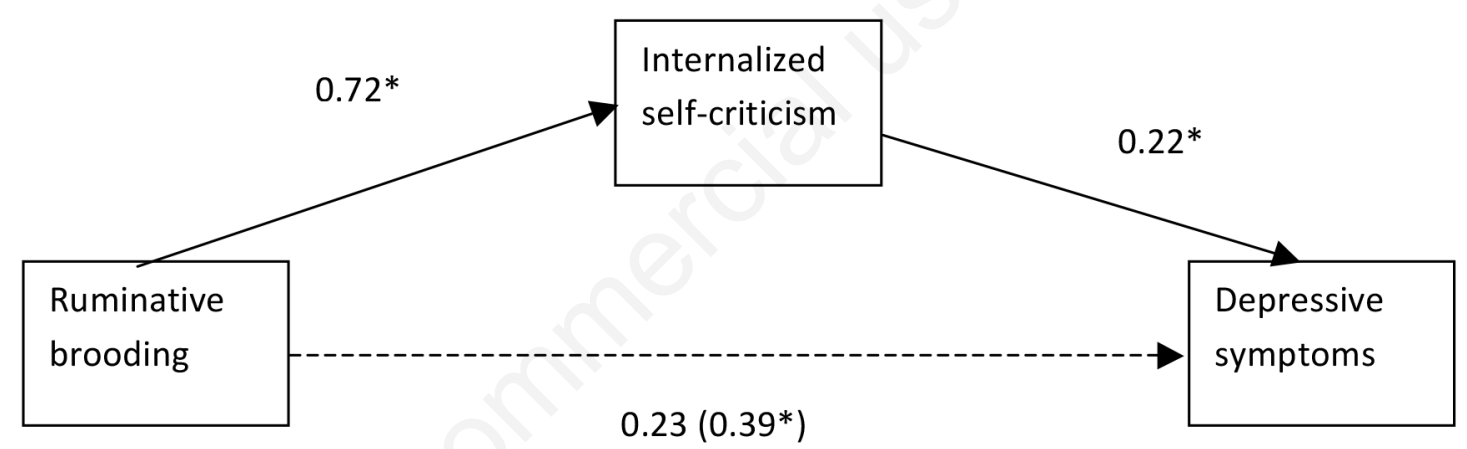

Figure 2. Change in internalized self-criticism completely mediated the effect of ruminative brooding on change in depressive symptoms. Parameter estimates are standardized coefficients. The value in parentheses is the standardized coefficient of the direct effect of ruminative brooding without internalized self-criticism entered in the model. Bootstrap $\operatorname{samples}=1000 .{ }^{*} \mathbf{P}<0.05$.

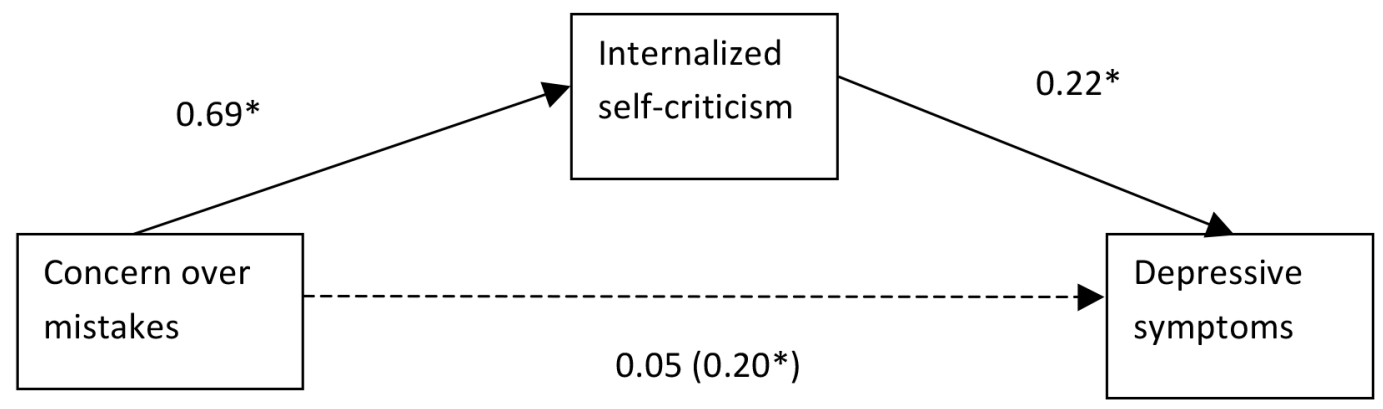

Figure 3. Change in internalized self-criticism completely mediated the effect of concern over mistakes on change in depressive symptoms. Parameter estimates are standardized coefficients. The value in parentheses is the standardized coefficient of the direct effect of concern over mistakes without internalized self-criticism entered in the model. $B$ ootstrap samples $=1000$. $* P<0.05$. 
controlling for ISC, suggesting a complete mediation relationship.

\section{Discussion}

In the present research, we investigated how much perceived parental criticism, perfectionistic $\mathrm{CM}$ and ruminative B could predict the level of ISC, as well as the influence of all the variables considered on the presence and strength of depressive symptoms. Data analyses indicated that all the variables assessed could individually predict the dependent variables, but when analyzed together in order to predict levels of ISC first, and depressive symptoms secondly, perceived parental criticism lost its predictive power, showing the complete mediating role of CM and B on ISC, and of ISC on depressive symptoms.

Focusing on the first part of the analyses, results showed that a psychological attitude characterized by $\mathrm{CM}$ and ruminative $\mathrm{B}$ enhanced the probability of determining a self-critical adult over and above the perception of having had high critical parents. We can hypothesize that perceiving parents as strongly critical can influence the tendency to self-criticize and, as a consequence, to be more vulnerable in manifesting depressive symptoms in two possible ways: an interpersonal way (perceived parental criticism may lead to a cognitive vulnerability to critiques made by others) and an internalized way (children may directly learn to relate to themselves in the same critical way parents used to relate to them) (Brewin et al., 1996). Self-criticism may then result as a strategy employed in order to continuously correct oneself and thus avoid the possibility of receiving critiques by others and having to cope with the related emotional grief. Finally, it is possible that perceiving parents as critical, most of all in a period of life when they should teach the child functional coping styles, can develop a passive cognitive control strategy employed in order to analyze all the negative external and internal events through self-focused attention (ruminative B) that may in turn sustain an internal and generalized locus of control and the attribution of responsibility for failures (ISC).

Focusing on the second part of our analyses, ISC can predict depressive symptoms over and above $\mathrm{CM}$ and ruminative $\mathrm{B}$. The complete mediating role of ISC in the relationship between perceived parental criticism and depressive symptoms replicated the findings of previous studies (Bolton et al., 2009; Brewin et al., 1996; Enns, Cox, \& Larsen, 2000; Sachs-Ericsson et al., 2006), while the strengths of ISC in predicting depressive symptoms over and above CM replicated a study by Dunkley, Zuroff, and Blankstein (2003), who found that the most robust predictor of maladjustment and depressive symptoms among perfectionism components was self-criticism and that self-criticism appeared to be a promising candidate to capture the most critical pathological component of perfectionism.
It is noteworthy that ruminative B could not directly predict depressive mood, as seen in the literature that indicated ruminative $\mathrm{B}$ as the most important factor in increasing the severity of depressed episodes (e.g., Nolen-Hoeksema, Parker, \& Larson, 1994) and prolonging them (Lyubomirsky \& Nolen-Hoeksema, 1995). In this sense, it seems that, among a non-clinical population, being self-critical facilitates depressive symptoms over and above being ruminative. Overall, we can suppose that these differences in the explanative role of B and selfcriticism can be due to the nature of the sample, who was not clinically depressed, but representative of the general population.

Concerning clinical implications, even considering the employment of a non-clinical sample, the findings of this research stressed the importance of assessing and addressing ISC as a dysfunctional cognitive habit employed to cope with both success and failure experiences, in order to prevent and treat depressive mood. In addition, the correlations found between all the variables considered and the meditational model emerging from the analyses stressed the need to consider more than one cognitive process in the case formulation and during the treatment of depressive symptoms, even from a developmental point of view. These results suggest moving beyond treatment protocols focused on the most probable dysfunctional process, towards modular protocols that may cover both core and elective topics selected on the basis of a more detailed case formulation. In this sense, for example, clinical interventions focused on $\mathrm{CM}$ and ruminative B could impair negative effects of ISC and, in turn, weaken depressive symptoms: learning how to tolerate the possibility of being mistaken could lead the person to be less critical towards his or her standards. Finally, addressing ruminative B and replacing it with an active problem solving process can lead the person to reach a major sense of self-efficacy and weaken the tendency to self-criticize, lessening in turn depressive symptoms.

The limitations of this research included the use of a non-clinical sample, with a broad age range and mostly composed by females: these aspects narrow the clinical relevance of the results. Moreover, we did not have the possibility to directly manipulate the variables considered, so it was not possible to identify causal relationships but only correlational and predictive links. All the results presented the limits typical of the self-report instruments employed, like social desirability, self-report biases and context effect that could have contributed to mistakes and distortions in self-reporting. Given the retrospective nature of some measures employed (such as the evaluation of perceived parental criticism), it is possible that some difficulties in recall might have contributed to distortion and biasing of participants' answers. Again, negative life events were not assessed, and this represents a limit considered the high correlation among this aspect and depressive symptoms. Fi- 
nally, the sample was entirely Caucasian and thus limits the possibility of generalizing the results.

\section{Conclusions}

Future research could further investigate the role of perceived parental criticism in becoming self-critical and further explore the relationship between self-criticism and depressive symptoms. In this view, it could be helpful to develop a longitudinal study that enables observing and assessing these variables over time. Moreover, it could be helpful both to extend the investigation to a wider population, and to try to replicate it among a clinical sample of depressed patients, in order to address possible similarities between the samples and better understand the differences; in this way, it would be interesting to address possible differences in the relationship between the variables on a continuum of patients with different levels of depressive symptoms, aiming to observe possible differences in cognitive functioning depending on the levels of symptom severity. Finally, it could be helpful to evaluate the mediating role of direct changes in ISC, ruminative $\mathrm{B}$ and $\mathrm{CM}$ during psychological interventions in the reduction of depressive symptoms in the context of prospective studies.

\section{References}

Apparigliato, M., Ruggiero, G.M., \& Sassaroli, S. (2007). Il Perceived Criticism Inventory: un nuovo strumento di valutazione del criticismo genitoriale [Perceived Criticism Inventory: a new questionnaire for the assessment of parental criticism]. Psicoterapia Cognitiva e Comportamentale, 13(3), 275-300.

Baldwin, M.W. (1992). Relational schemas and the processing of social information. Psychological Bulletin, 112, 461-484.

Baldwin, M.W. (1997). Relational schemas as a source of if-then self-inference procedures. Review of General Psychology, 1, 326-335.

Beck, A.T., Rush, A.J., Shaw, B.F., \& Emery, G. (1979). Cognitive therapy of depression. New York, NY: Guilford Press.

Beck, A.T., Steer, R.A., \& Garbin, M.G. (1988). Psychometric properties of the Beck Depression Inventory: Twenty-five years of evaluation. Clinical Psychology Review, 8, 77-100. doi:10.1016/0272-7358(88)90050-5

Beck, A.T., Ward, C.H., Mendelson, M., Mock, J., \& Erbaugh, J. (1961). An inventory for measuring depression. Archives of General Psychiatry, 4, 561-571. doi:10.1001/archpsyc.1961. 01710120031004

Bolton, C., Barrowclough, C., \& Calam, R. (2009). Parental criticism and adolescent depression: does adolescent self evaluation act as a mediator? Behavioural and Cognitive Psychotherapy, 37(5), 553-570. doi: 10.1017/S135246580 9990221

Bowlby, J. (1980). Loss: Sadness and depression. Attachment and loss (Vol. 3). London: Hogarth Press.

Brewin, C.R., Andrews, B., \& Furnham, A. (1996). Self-critical attitudes and parental criticism in young women. British Journal of Medical Psychology, 69(1), 69-78.

Cox, B.J., Enns, M.W., \& Clara, I.P. (2004). Psychological dimen- sions associated with suicidal ideation and attempts in the National Comorbidity Survey. Suicide and Life-Threatening Behaviour, 34(3), 209-219. doi: 10.1521/suli.34.3.209.42781

Cox, B.J., Fleet, C., \& Stein M.B. (2004). Self-criticism and social phobia in the US national comorbidity survey. Journal of Affective Disorders, 82(2), 227-234. doi:10.1016/j.jad. 2003.12.012

Cox, B.J., Mac Pherson, P.S., Enns, M.W., \& McWilliams, L.A. (2004). Neuroticism and self-criticism associated with posttraumatic stress disorder in a nationally representative sample. Behaviour Research and Therapy, 42(1), 105-114. doi:10.1016/S0005-7967(03)00105-0

Dunkley, D.M., \& Grilo, C.M. (2007). Self-criticism, low selfesteem, depressive symptoms, and over-evaluation of shape and weight in binge eating disorder patients. Behaviour Research and Therapy, 45(1), 139-149. doi:10.1016/j.brat. 2006.01.017

Dunkley, D.M., Masheb, R.M., \& Grilo, C.M. (2010). Childhood maltreatment, depressive symptoms, and body dissatisfaction in patients with binge eating disorder: the mediating role of self-criticism. The International Journal of Eating Disorders, 43(3), 274-281. doi: 10.1002/eat.20796

Dunkley, D.M., Zuroff, D.C., \& Blankstein, K.R. (2003). Selfcritical perfectionism and daily affect: dispositional and situational influences on stress and coping. Journal of Personality and Social Psychology, 84, 234-252. doi: 10. 1037/0022-3514.84.1.234

Enns, M.W., Cox, B.J., \& Larsen, D.K. (2000). Perceptions of parental bonding and symptom severity in adults with depression: mediation by personality dimensions. Canadian Journal of Psychiatry, 45(3), 263-268.

Fazaa, N., \& Page, S. (2003). Dependency and self-criticism as predictors of suicidal behavior. Suicide and Life-Threatening Behaviour, 33(2), 172-185.

Fennig, S., Hadas, A., Itzhaky, L., Roe, D., Apter, A., \& Shahar, G. (2008). Self criticism is a key predictor of eating disorder dimensions among inpatient adolescent females. International Journal of Eating Disorders, 41, 762-765. doi: 10. 1002/eat.20573

Frost, R.O., Marten, P., Lahart, C., \& Rosenblate, R. (1990). The dimensions of perfectionism. Cognitive Therapy and Research, 14, 449-468. doi: 10.1007/BF01172967

Frost, R.O., Turcotte, T.A., Heimberg, R.G., Mattia, J.I., Holt, C.S., \& Hope, D.A. (1995). Reactions to mistakes among subjects high and low in perfectionistic concern over mistakes. Cognitive Therapy and Research, 19(2), 195-205. doi: 10.1007/BF02229694

Ghisi, M., Flebus, G.B., Montano, A., Sanavio, E., \& Sica, C. (2006). Beck Depression Inventory-II. BDI-II. Manuale. Firenze: O.S. Organizzazioni Speciali.

Gibb, B.E. (2002). Childhood maltreatment and negative cognitive styles. A quantitative and qualitative review. Clinical Psychology Review, 22(2), 223-246. doi: 10.1016/S02727358(01)00088-5

Hartlage, S., Arduino, K., \& Alloy, L.B. (1998). Depressive personality characteristics: State dependent concomitants of depressive disorders and traits independent of current depression. Journal of Abnormal Psychology, 107, 349-345.

Hayes, A.F. (2013). Introduction to mediation, moderation and conditional process analysis. A regression-based approach. New York, NY: Guilford Press.

Just, N., \& Alloy, L.B. (1997). The response styles theory of depression: Tests and an extension of the theory. Journal of 
Abnormal Psychology, 106, 221-229. doi: 10.1037/0021843X.106.2.221

Kasch, K.L., Klein, D.N., \& Lara, M.E. (2001). A construct validation study of the Response Styles Questionnaire Rumination scale in participants with a recent-onset major depressive episode. Psychological Assessment, 13(3), 375383. doi: 10.1037/1040-3590.13.3.375

Lobera, I.J., Estébanez, S., Fernandez, M.J., Bautista, E.A., \& Garrido, O. (2009). Coping strategies in eating disorder. European Eating Disorder Review, 17(3), 220-226. doi: 10.1002/erv.920

Luyten, P., Sabbe B., Blatt, S.J., Meganck S., Jansen B., De Grave, C., ..., Corveleyn, J. (2007). Dependency and selfcriticism: relationship with major depressive disorder, severity of depression, and clinical presentation. Depression and Anxiety, 24, 586-596. doi: 10.1002/da.20272

Lyubomirsky, S., \& Nolen-Hoeksema, S. (1995). Effects of selffocused rumination on negative thinking and interpersonal problems [Electronic version]. Journal of Personality and Social Psychology, 69, 176-190.

Marshall, M.B., Zuroff, D.C., McBride, C., \& Bagby, R.M. (2008). Self-criticism predicts differential response to treatment for major depression. Journal of Clinical Psychology, 64, 231-244. doi: 10.1002/jclp.20438

McCranie, E.W., \& Hyer, L.U. (1995). Self-critical depressive experience in posttraumatic stress disorder. Psychological Reports, 77, 880-882. doi: 10.2466/pr0.1995.77.3.880

Neff, K. (2003). Self-compassion: An alternative conceptualization of a healthy attitude toward oneself. Self and Identity, 2, 85-101. doi: 10.1080/15298860309032

Nolan, S.A., Roberts, J.E., \& Gotlib, I.H. (1998). Neuroticism and ruminative response style as predictors of change in depressive symptomatology. Cognitive Therapy and Research, 22, 445-455. doi: 10.1023/A:1018769531641

Nolen-Hoeksema, S. (1991). Responses to depression and their effects on the duration of depressive episodes. Journal of Abnormal Psychology, 100(4), 569-582. doi: 10.1037/0021843X.100.4.569

Nolen-Hoeksema, S., \& Davis, C.G. (1999). 'Thanks for sharing that': Ruminators and their social support network. Journal of Personality and Social Psychology, 77, 801-814.

Nolen-Hoeksema, S., \& Morrow, J. (1991). A prospective study of depression and posttraumatic stress symptoms after a natural disaster: The 1989 Loma Prieta earthquake. Journal of Personality and Social Psychology, 61, 115-121. doi: 10.1037/0022-3514.61.1.115
Nolen-Hoeksema, S., Parker, L.E., \& Larson, J. (1994). Ruminative coping with depressed mood following loss [Electronic version]. Journal of Personality and Social Psychology, 67, 92-104. doi: 10.1037/0022-3514.67.1.92

Olson, M.L., \& Kwon, P. (2008). Brooding perfectionism: refining the roles of rumination and perfectionism in the etiology of depression. Cognitive Therapy and Research, 32(6), 788-802. doi: 10.1007/s10608-007-9173-7

Palmieri, R., Gasparre, A., \& Lanciano, T. (2007). Una misura disposizionale della ruminazione depressiva: la RRS di Nolen-Hoeksema e Morrow [A questionnaire to assess dispositional depressive rumination: Nolen-Hoeksema and Morrow's RRS]. Psychofenia, 17, 15-33. doi: 10.1285/i1 $7201632 \mathrm{vXn} 17 \mathrm{p} 15$

Parker, G., \& Crawford, J. (2009). Personality and self-reported treatment effectiveness in depression. The Australian and New Zealand Journal of Psychiatry, 43(6), 518-525. doi: 10.1080/00048670902873730

Powers, T.A., \& Zuroff, D.C. (1992). A measure of overt selfcriticism: Validation and correlates. Psychological Reports, 70(2), 562. doi: 10.2466/pr0.1992.70.2.562

Preacher, K.J., \& Hayes, A.F. (2008). Asymptotic and resampling strategies for assessing and comparing indirect effects in multiple mediator models. Behavior Research Methods, 40, 879-891. doi: 10.3758/BRM.40.3.879

Rose, D.T., \& Abramson, L.Y. (1992). Developmental predictors of depressive cognitive styles: developmental perspectives on depression. In D. Cicchetti \& S.L. Toth (Eds.), Developmental perspectives on depression (Vol. 4, pp. 323-349). Symposium on Developmental Psychopathology: Developmental perspectives on depression, Rochester, NY.

Sachs-Ericsson, N., Verona, E., Joiner, T., \& Preacher, K.J. (2006). Parental verbal abuse and the mediating role of selfcriticism in adult internalizing disorders. Journal of Affective Disorder, 93(1-3), 71-78. doi:10.1016/j.jad.2006.02.014

Spasojevic, J., \& Alloy, L.B. (2001). Rumination as a common mechanism relating depressive risk factors to depression. Emotion, 1(1), 25-37. doi: 10.1037/1528-3542.1.1.25

Thompson, R., \& Zuroff, D.C. (2000). The levels of self-criticism scale. Poster session: APA: Assessment and diagnosis, Washington Convention Center, Washington, DC, USA.

Thompson, R., \& Zuroff, D.C. (2004). The levels of self-criticism scale: Comparative self-criticism and internalised selfcriticism. Personality and Individual Differences, 36, 419-430. 